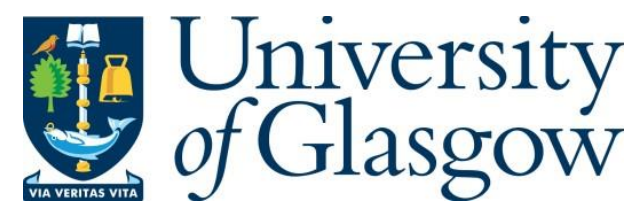

Valdera Gil, F. and Crichton, H. (2018) Mother tongue plus two languages: are Scottish Primary Teachers confident to deliver? Language Learning

Journal, (doi:10.1080/09571736.2018.1448430)

There may be differences between this version and the published version. You are advised to consult the publisher's version if you wish to cite from it.

http://eprints.gla.ac.uk/158469/

Deposited on: 25 April 2018

Enlighten - Research publications by members of the University of Glasgow http://eprints.gla.ac.uk 


\section{Mother Tongue plus two Languages: are Scottish Primary Teachers confident to deliver?}

Francisco Valdera Gil and Hazel Crichton

The School of Education, University of Glasgow

Francisco.Valdera-Gil@glasgow.ac.uk

Hazel.Crichton@glasgow.ac.uk

Recent policy reforms in Scotland mean that all primary teachers are expected to teach a foreign language (FL) to children from age 5, introducing a second language around age 9. This small-scale research study aimed to ascertain 38 primary teachers' perceptions of their confidence to teach a FL to primary learners and what they felt would be helpful in developing their language proficiency and language teaching pedagogy. The teachers, while enthusiastic about the thinking behind the policy, expressed concern about their ability to provide a good model of language to their classes and their own development as learners of a language while simultaneously having to teach it. FL assistants, secondary colleagues and FL development officers were seen as valuable sources of support, but questions were raised about the sustainability of the policy without long-term permanent commitment.

Keywords: primary foreign language learning; teacher language confidence; teacher perceptions of policy reform

In 2012 the Scottish Government announced a manifesto commitment to implement by 2020 a model for language learning based on the European Union ' $1+2$ model', that is, mother tongue, plus two FLs, for the whole of its school age population (Scottish Government, 2012a). This policy was first ratified at the European Council of Barcelona in 2002, which is why it is also known as the 'Barcelona agreement'. The aim of the agreement was to engage the $450+$ million European Union (EU) citizens in lifelong learning and develop their skills to communicate with their neighbours, in at least two languages other than their mother tongue to encourage mobility. The UK was a signatory to this agreement.

In European countries such as Spain, France and Germany, children learn a FL, often English, as part of their primary education, starting from approximately seven years of age (Ministerio de Educación, Cultura y Deporte 2012, Kultus Minister 2013, Ministère de l'Education l'Enseignement National 2016). In order to fulfil this commitment, teachers in primary schools are required to have a level of at least B2 in the Common European Framework, which is assessed by a national examination before they are allowed to teach the FL (Ministerio de Educación, Cultura y Deporte 2012, Lohmar and Eckhardt 2014, Ministère de l'Education l'Enseignement National 2016).

With regard to early language learning in the UK, in England, despite language learning having been compulsory for children aged 7-11 since 2014, implementation appears to be mixed and some concerns have been raised about the quality and quantity of provision (Board 
and Tinsley, 2015).In Northern Ireland there is a languages strategy with a series of recommendations for primary age children (Gillespie et al., 2012), but it is unclear whether they have been acted upon systematically. In Wales, Welsh language learning is compulsory for all pupils aged 5-16 (Jones, 2001). However, it appears that the cognitive benefits of bilingualism when learning other languages have not been exploited, with only $22 \%$ of Welsh pupils taking a General Certificate of Education (GCSE) in a language other than Welsh or English (Tinsley and Board, 2016). Scotland appears to be the only part of the UK where the educational, business and personal benefits to learning languages have been recognised in a clear policy which is being enacted in the classroom.

It could be argued that the Scottish Government has shown great vision in promoting the learning of languages as part of a policy to ensure that Scots are well equipped citizens of a multi-lingual, multi-cultural, globalised world. Their aspiration for all primary school children to learn two languages additional to their mother tongue $(1+2)$ by 2020 (Scottish Government, 2012a) is to be commended. At the mid-point of the initiative, it is perhaps timely to assess its progress. Within this initiative, which began its implementation in 2012, the primary class teacher has responsibility for embedding language learning within the daily life of the classroom. The research study described in this article aimed to determine how a group of primary teachers' perceived the success or otherwise of the initiative thus far and any challenges that they had had to face.

The questions that the study aimed to answer were as follows:

- Do primary teachers in Scotland feel confident to deliver the $1+2$ ?

- Going forward, what support do these primary teachers perceive as valuable?

In order to understand the context of the study, the policy will firstly be explained. It is important to highlight that Education in Scotland is a devolved area, along with Law and Health, for which the Scottish Government has full decision-making and regulatory responsibility. The Scottish education system, therefore, cannot be assumed to be the same as in the rest of the UK. After the context has been set, there will be discussion of what the literature says about early language learning and findings from studies into language learning which have taken place in the primary context, both in the UK and in other countries. The methodology of the study will then be described, followed by an account of the findings and conclusions.

\section{Mother tongue plus two FLs (1+2)}

In Scotland in 2012, the Languages Working Group, representing practitioners, policymakers, local authorities, teacher educators, parents and business interests, produced a report which included 35 recommendations regarding language learning in Scotland (Scottish Government, 2012a). 31 of the recommendations were fully accepted; the other four were partially accepted by the Scottish Government (Scottish Government, 2012b) and moves were made to make the recommendations a reality. The report concentrated mainly on early language learning although there were a number of recommendations which concerned 
language learning and teaching in the secondary school and teacher education. Despite being ten years behind the rest of Europe regarding language learning policy it seemed a bold move, which recognised the need for young Scots to be able to compete globally in professional and educational domains.

While the general consensus was that this was a visionary move, there were some, among them Local Authority (LA) representatives, parent organisations and academics who, while welcoming the initiative, voiced concerns as to whether the policy was achievable, citing financial and training issues (Scottish Parliament, External Relations Committee, 2013). There appeared to be an assumption that universities would change entry requirements to include a language qualification for those applicants wishing to undertake primary teacher education programmes (General Teaching Council Scotland (GTCS) 2013). However, the recommendations of the Languages Working Group regarding teacher education were among those only partially accepted by the Government, who indicated that the universities themselves should decide what entry tariffs should be imposed.

The documentation surrounding the $1+2$ policy is very positive about the benefits of an early start to language learning (Education Scotland, 2015:1) basing arguments on the 'considerable body of evidence which indicates that young children learn languages more easily than older learners' (Scottish Government 2012a.). However, it seems surprising that the established research evidence regarding early language learning seems to have been ignored or not consulted. According to Tierney and Gallestegi (2013), research is not conclusive on the benefits of an early start for second language acquisition. There appears to be a lack of empirical evidence to date confirming that younger starters overtake older starters in school settings with the same amount of input. (García Mayo 2003; Muñoz 2008; Muñoz and Singleton 2011).

The Barcelona Age Factor study (BAF) led by Muñoz (2006b), followed over 2,000 Spanish learners of English in instructional settings at different starting points through primary and secondary schooling, to their mid-20s. This study challenged the widely accepted idea of 'the earlier the better', concluding that the major benefit of starting learning languages in the primary school were attitudinal, not linguistic. Younger starters showed more enthusiasm for learning languages, but did not achieve superior mastery of the language compared to those starting later, who demonstrated greater cognitive advantages which enabled them to learn language quicker and more effectively. The study does not suggest that language learning should not start in the primary years but demonstrates how later starters can gain the same level of language proficiency given the same time and exposure to the language. Even before Muñoz's pioneering study, researchers were warning about drawing conclusions from the context of second language learning and applying them to language learned as a FL solely in the classroom (Cenoz 2003). García Mayo's research into Basque children's acquisition of English as an L3 suggested that, given the same amount of exposure to the FL, learners beginning at a later stage actually outperformed those who had begun earlier (2003). Most recently, Myles (n.d.) has noted that early language learning has 'great potential', but her research project conducted in the North of England, reinforces previous research findings that earlier does not mean better in a FL context. 
Many studies of early second language acquisition have been conducted with learners in a bilingual or immersion context, (see, for example, Cummins 2000, 1991; Bialystock 2008), which can be regarded as very different to a monolingual classroom setting where learners are taught a limited repertoire of expressions with few opportunities for 'real' practice communicating with native speakers of the language. The difference between naturalistic language learning and FL learning is often not taken into account when discussing maturational constraints (Cenoz 2003; Muñoz 2008).

In Scotland, Gaelic medium education has been cited as an example of successful second language teaching (Johnstone et al. 1999; O'Hanlon et al. 2010). Gaelic medium education follows immersion principles which have been found to be successful in developing nativelike second language proficiency (Paradis et al. 2003). In a partial immersion context, where children are taught for part of the time in another language, results have been shown to be similar (Johnstone and McKinstry, 2008; Crichton and Templeton, 2010). However, these contexts are very different to that of most primary schools, where exposure to the FL may be restricted at most to an hour per week. Weaknesses have been identified concerning Gaelic medium education with regard to suitably qualified staff, professional development and training (Her Majesty's Inspectors of Education, 2011).

These same issues could be regarded as critical for the success of primary level FL learning. The Nuremberg Recommendations for Early Learning (Goethe Institut 2010) stipulate that teachers of primary FLs should be 'fully fluent in age-appropriate variants of the target language', but it appears that qualified staff is not seen as a priority by the Scottish Government: 'In line with the guidance for teaching a first modern language in P1, (that is, the first year of primary school, when children are 4-5 years old) primary practitioners do not have to be fluent in the language(s) they teach.' (Education Scotland n.d.) Instead, teachers are expected to access materials to enable them to incorporate the language on a daily basis into their classroom practice. In the same document, teachers are given lists of expected outcomes for each level of primary education. There is no indication of the expected level of teacher language proficiency.

Teachers' lack of fluency and therefore reluctance to use the language is an issue which was identified in secondary schools by Meiring and Norman (2002). Franklin's (1990) research with Scottish secondary teachers, all with degrees in the languages they taught, found that $83 \%$ cited lack of confidence as an excuse for not using the language in the classroom.

Research with English as a FL teachers has found similar problems of fluency, accuracy and confidence, despite a high level of qualification (Klanrit and Sroinam, 2012). In the primary school, where most practitioners are generalists, a lack of understanding of the language they will teach may produce similar or greater issues regarding confidence. Tierney (2011) and Barton and Boodhoo (2009:141) conclude that 'There are problems in introducing foreign languages to younger learners which we ignore at our peril'.

In view of the arguments surrounding early foreign and subsequent language learning and suitable training for primary teachers, it seemed appropriate to consult the teachers themselves who have responsibility for implementing the 1+2 policy. We were keen to find 
out whether they felt confident to embed the FL within the curriculum, as recommended in the documentation, and what they saw as useful to support them.

\section{The study}

\section{Particpants}

The participants in the study were 38 primary teachers from four Scottish local authorities (LAs) who had recently taken part in professional development courses, focused on development of language skills and pedagogy in Spanish or French in preparation for implementing the $1+2$. The sample could be described as a convenience, or non-probability sample, due to the easy proximity of access. While non-probability sampling limits possibilities for generalising the results (Etikan et al., 2016), we felt it was useful to flag up any issues that an enthusiastic and positive cohort, as evidenced by their commitment to the courses, had identified. We were also keen to assess whether they felt the courses had been helpful in preparing them to enact the policy, thus assisting those with responsibility for delivery of the courses to evaluate and improve provision. The teachers represented a wide range of experience from 3-21 years teaching, with no particular group dominating. There also appeared to be a fairly equal distribution of those teachers with undergraduate and postgraduate primary teaching qualifications. The teachers' linguistic capabilities ranged from declared no knowledge of French or Spanish to degree level competence.

\section{Questionnaires and interviews}

The 38 participants completed short questionnaires, comprising seven closed and three open questions which aimed to ascertain their perceptions of their own competence linguistically after the course and how confident they felt in delivering the language in their classrooms. The questionnaires were designed to enable identification of what the teachers felt to be key issues of interest or concern regarding the impact of the policy on their practice. The closed questions included items with Likert scale responses such as: 'How confident do you feel about incorporating French or Spanish into your daily routine?'; 'How confident do you feel that you can provide a good model of pronunciation of French/Spanish to your class?'; 'How much support have you been given to enact the 1+2 policy?'. The more open questions asked: 'What are your thoughts on the 1+2 as a policy?'; 'What have you found particularly helpful in enacting the 1+2 so far?' and 'What would you say are your immediate professional development needs with regard to the $1+2$ ?'.

Questionnaires are often held to be an effective way of recognising themes which can then be explored further in interviews (Bryman, 2015). The questionnaire data were scrutinised by each researcher individually before coming together to deliberate and agree which issues could be seen as most prominent. Most of the teachers appeared non-committal in the closed questions, preferring to choose responses around the middle of the scales, which indicated that they neither agreed nor disagreed strongly with the items. However in the open questions, they seemed more forthcoming, perhaps because they were not being asked 
specifically about their practice. Some of the open responses provided insights into their understanding of language learning, concerns about the implementation of the $1+2$, and their role as teachers of at least one FL in the classroom. Thus, a number of themes were identified which centred round teacher confidence, ease of integration of the FL, formal and informal support and ongoing and future needs. The general tendencies arising from the questionnaire data suggested that the teachers were cautiously optimistic about the $1+2$, but appeared to be lacking in confidence regarding how they could develop their own language knowledge and pedagogical approaches which might support learners to gain a clear understanding of the form and structure of the language.

These themes identified from the questionnaires were then explored in greater depth through semi-structured individual interviews with 10 of the teachers, who were selected from volunteers to represent the diversity of qualifications, experience and linguistic competence of the participants. Details of the 10 teachers can be seen in Appendix 1, with an explanation of the different levels of Scottish qualification at school, undergraduate and postgraduate stages.

Although we had prepared ten interview questions, we were very much led by the participants regarding the areas they felt were important. One of the strengths of semistructured interviews is that they allow the participants to probe relevant areas of interest which arise (Silverman, 2005). The questions in the interviews were framed around the following themes:

- Teachers' evaluation of their own language competence: questions were asked about levels of fluency and confidence in using the language in everyday practice; possible concerns related to specific areas of language, for example, pronunciation, grammar, vocabulary; experience using the language with native speakers.

- Teachers' evaluation of their readiness to implement 1+2 language policy: this section of the interview centred on pedagogy and resources. Were they aware of materials and resources apart from those which had been supplied? Would they be able to adapt authentic materials to suit different ages and stages of learners?

- Perceived opportunities and challenges: teachers were encouraged to reflect on what they saw as the benefits of teaching a FL and also what they would find most challenging in doing so in the primary classroom.

- Changes, if any, to teaching and learning approaches: Teachers were asked about their awareness of approaches to learning and teaching French and/or Spanish and which they intended to make most use of.

- Evaluation of professional development courses and next steps: finally, the teachers were asked about the content of the courses they had taken part in and what they saw as their targets for future action. 
Each interview lasted approximately one hour. We were keen that the interviews should be collaborative and 'responsive' (Rubin and Rubin, 2012), so that the teachers' views of what was important was the driver of the interview (Flick, 2014). Therefore, the teachers were encouraged to elaborate and on occasions, to digress, to ensure that their concerns and considerations were fully communicated. We were also conscious, as language specialists ourselves, that we should frame our questions sensitively, so that the teachers should not feel defensive about possible deficiencies in language skills but see the interview as 'drawing on mutually familiar ... experiences' (Holstein and Gubrium, 1995:77), so that any potential issues of power could be minimised (Plesner, 2011). The interviews were recorded and transcribed as soon as possible after they had taken place to ensure that notes about specific impressions of non-verbal and para-linguistic behaviours could be added to enrich the data (Stein et al., 2013) while they were fresh in mind.

As with the analysis of the questionnaire data, we examined the transcripts individually, before coming together to discuss the main themes each one of us had identified from the interview data. Carey et al. (1996) argue that validity and reliability are strengthened in qualitative research through inter-coder agreement. Taking a grounded approach and using the research questions as organisers in our discussions, we agreed initial codes (Charmaz, 2006). The data were further analysed individually, following a more focused coding process, before reconvening to agree the core categories (Strauss, 1987), or 'story lines' (Strauss and Corbin, 2008) emerging from the data.

During the coding process, it was important to bear in mind our own roles and beliefs as teacher educators and linguists, keeping our 'eyes open', but at the same time making no assumptions or judgements about the issues raised by the teachers (Asselin, 2003).

Sensitising concepts refer to the researchers' background knowledge which is often used to define the issue under investigation and may be used as 'points of departure' when beginning the analysis of the data (Charmaz, 2003: 259). Our experience afforded us 'a general sense of reference and guidance in approaching empirical instances.' (Blumer: 1954:7). Nonetheless, we were keen to avoid constructing meaning influenced by fixed notions of what we might expect to find. Bearing in mind the need to maintain a reflexive attitude acknowledging the 'impossibility of remaining 'outside of' one's subject matter while conducting research' (Nightingale and Cromby, 1999: 228), it nevertheless seemed inappropriate to attempt to ignore what prior knowledge might bring to the analysis.

Ensuring credibility was seen as paramount in determining trustworthiness (Lincoln and Guba, 1985) and by maintaining as objective a stance as possible and detailing all the steps of the data collection and analysis, we aimed to demonstrate as much rigour as possible in this qualitative study.

The responses of the teachers were very similar. As noted above, they responded fairly neutrally in the questionnaire, particularly to the closed questions, however, the interviews provided rich data for analysis, thus, while not ignoring the questionnaire data, the subsequent interviews provided a much deeper understanding of the teachers' perceptions of the enactment of the policy, their confidence as language teachers in the primary classroom 
and their perceived needs. It was therefore decided that the analysis of the interview data would form the basis of the findings, which will be described below.

\section{Findings}

The findings of the semi-structured interviews were organised into themes which aimed to answer the two central questions of this research:

- Do primary teachers feel confident to deliver the $1+2$ ?

- Going forward, what support do primary teachers perceive as valuable?

As stated above, the thirty-eight primary teachers who took part in the initial questionnaire of this research had volunteered to participate in a programme of professional development to improve their FL skills in French and Spanish and their understanding of methodology for modern languages learning and teaching for two hours a week after school over 18 weeks. The course attendance, in addition to the commitment of extra home learning and preparation, meant they were likely to be supportive of the $1+2$ initiative and had used their agency to improve their language skills. Whilst critical on occasions, they were supportive overall of the idea of bringing the learning of FLs to younger learners and they appeared to be trying their best to make it work: 'Finally, Scotland is catching up with the rest of Europe' (Teacher 3); 'It was about time that this country did what is done in other countries.'

(Teacher 7). It cannot be assumed that all the primary teachers in Scotland have the same enthusiasm, time, nor level of engagement for modern languages professional development. The responses to each research question will now be described below:

\section{Do primary teachers feel confident to deliver the $1+2$ ?}

The primary teachers who took part in this study were taking part in professional development of language learning activities in their own time, because they had recognised their lack of language skills. It should not come as a surprise that they were aware of their language needs, their perceived success and future development needs in language learning and pedagogy, when asked to reflect upon them in an interview. With regard to their own confidence most of them felt they had benefitted from the course. 'I feel more confident now, after the course, than I did before. However, I still need to work on my pronunciation' (Teacher 6). The issue of teacher self-efficacy and different levels of language confidence, or lack of it, could be discerned in the responses of every interviewee. 'I wouldn't say that I was confident, but I feel I will be able to teach French' (Teacher 7). However, their responses regarding the initiative were often contradictory, suggesting that they had an equivocal understanding of the underpinning philosophy and what was intended regarding the policy.

When asked about their readiness for implementing the $1+2$ policy, most of the teachers expressed cautious optimism. A number of the teachers were from one LA, which was promoting Hattie's 'Visible Learning' framework (2012). Hattie undertook a meta-analysis of over 800 studies into improvement in learner outcomes and identified the greatest influential 
factors in learner achievement. Visible learning refers to teachers looking at learning through the eyes of the learner, providing formative feedback to improve performance, regarding errors as learning opportunities, all of which were identified as having major roles to play in improving learning outcomes. The teachers appeared to have applied the framework to themselves as learners; reflecting upon their learning and the feedback they got, regarding mistakes as opportunities for further learning and planning their next steps. This group of teachers who were 'language beginners' displayed a very optimistic stance to their own language learning: 'It is all Visible Learning; you are allowed to make mistakes, so it doesn't matter' (Teacher 2). 'Some of the best practices HMIe have said is when they are going into the classroom and the teachers are learning with the children' (Teacher 9).

It was not clear if the teachers really believed what they were saying or whether they were using a face-saving strategy to cover their insecurity regarding their language proficiency. Teacher 2's assertion that mistakes 'didn't matter' seems to indicate a less than secure understanding of the Visible Learning concept, particularly when she claimed later in the interview: ' 'They are just sponges, they just take everything, taking it in, remembering it...' . Despite enthusiastically having embraced the teaching of languages, when considering both quotes, there is the worrying implication that the children may also 'take in' and 'remember' the teacher's mistakes, if she is not assiduous in correcting them.

While asserting that making mistakes was acceptable, as both teachers and learners were undertaking the same learning journey, it seemed clear, when asked about opportunities and challenges that the policy would bring, that most of the teachers were anxious that the children were not explicitly taught incorrect language form. 'I think I can manage the pronunciation, but I forget which gender is which and I don't want to tell the children the wrong thing' (Teacher 4). 'Grammar is an issue for me beyond the simple present tense and I'm not sure of the irregular verbs' (Teacher 8). Some of the teachers expressed concern regarding their perceived lack of knowledge of pronunciation of the modern language(s). ' $I$ am not confident about my pronunciation' (Teacher 1); : '... some people ... will never sound anything like real French. And they have to deliver that to the class, it is not very satisfying' (Teacher 6).

Although teachers showed enthusiasm about the initiative, recognising the benefits of language learning for children's cognitive development, most of those interviewed appeared to be apprehensive and uncomfortable about actually delivering a FL. Concerns about confidence regarding their pronunciation and grammar were echoed in their comments regarding enacting the policy on a regular basis. 'We are panicking...' (Teacher 6); 'I am not ready to teach French or any other FL'(Teacher 3). Their perceived lack of modern language(s) competence, either in one or both of the languages they were teaching, or about to start to teach, appeared to have affected their confidence.

'The children in the nursery this year will have had six years of French input by the time I teach them. I am not ready to teach that level of French or any other FL' (Teacher 1); 'I am 
very scared of teaching Spanish' (Teacher 5); 'Some teachers do not have any French or Spanish at all, and yet they are going to have to start introducing it and I think they are really panicking about it, they feel like impostors'. (Teacher 7)

As can be seen from the quotes above, the teachers expressed concern about their current level of language, along with fears regarding actually teaching a FL in the classroom, particularly in the later years of the primary school where the assumption was that the children's language competence would be greater. Teacher 1's fears that the learners would have a higher level of proficiency than she in the FL were echoed by most of the teachers of older children who were interviewed: 'I'm not sure that my level of language will be up to that of the children's when they come to my class' (Teacher 5). Brookfield's 'Impostor Syndrome' (1995) has been well documented and might be said to apply to the majority of those teachers who did not have qualifications in a FL, but even those who had studied languages to degree level, such as Teacher 7 still expressed apprehension about teaching them in the classroom: 'I studied French in my degree but that was a few years ago and it was all business related. There was no fun games and the kind of language that the children are learning now' (Teacher 7).

While Brookfield's description of teachers' feelings of insecurity is related to teaching in general, the pressure of having to deliver a FL appeared to have triggered the syndrome in otherwise confident teachers with a strong notion of self-efficacy. A possible consequence of these self-doubts may lead some teachers to avoid putting themselves in a position of vulnerability: '...the primary curriculum is so jammed packed with different things so it is difficult to find the time, to get that French in ...' (Teacher 5). When asked about any challenges to implementing the policy, almost half of the teachers cited lack of time due to the crowded nature of the primary curriculum, which meant it might be relatively easy for teachers to justify not having time to devote to language teaching. 'I'll be honest with you, if something comes up that's important, it's languages that goes out the window. I feel a bit bad about that, but we have to take the time from somewhere' (Teacher 4). Leaving aside whether languages can or should be seen as less important than any other event in the primary school curriculum, it may be that some teachers will use avoidance tactics regarding languages teaching, particularly if they are not confident in their own language abilities, or if they feel they are lacking support:

Most teachers, however, were able to identify support strategies which they said would be helpful. These are discussed below, where the second research question is addressed.

Going forward, what support do primary teachers perceive as valuable?

Many of the teachers had had experience of working with native speaker Conversation Assistants (CAs) the previous year and had found them an invaluable source of support, both as a model for pronunciation and also as a fluent speaker with a wide and varied language resource. 'It was very enriching to have $X$ with us. Her presence was an open door to France, pupils could listen to her pronunciation, and she could sing with them and talk about the culture of France. It has helped me develop professionally too' (Teacher 4). The contribution 
of the CAs to the understanding of another culture and the teachers' own development was echoed by a number of the teachers. 'The difference being taught by a native speaker, it seems to be huge, the accent is so much better, the children have a much better knowledge about France when they are taught by a native'. (Teacher 8). 'Last year Mr Y from the high school came to take my class once a week for half an hour, and it was a very good professional development for me' (Teacher 2). Continuing professional development was a clear need identified by all the teachers and those who had worked with CAs or secondary specialists were unequivocal about the advantages they had gained as learners and as teachers. Although they were employed to teach the children, the native speakers had provided perhaps previously unanticipated benefits for the teachers in terms of improved pronunciation, language structures and intercultural understanding.

In the absence of CAs the teachers identified a number of areas of support that they had found useful for their development as teachers of a FL. All the LAs had appointed 1+2 Development Officers who provided linguistic and pedagogic support. Most of those were secondary or primary specialists who had degrees in languages, whose remit was to provide support to the teachers, through on-going language/pedagogy events, resources and coteaching in the primary classroom role-modelling and 'coaching' primary teachers about language development and pedagogy. They were generally seen as very helpful, although the fixed term nature of these appointments also caused concern. '...the development officers, they have answered all our questions, they have come out and visited us. Where we have struggled to find information, they have guided us. But it has to be sustainable' (Teacher 9). The Scottish Government had pledged funding for the next academic year, but with conflicting priorities regarding children's development in literacy, numeracy and in particular Science, Technology, Engineering and Mathematics (STEM) subjects (Scottish Government, 2016a), there was the perception that funding for modern languages might be cut or discontinued. 'The money that the government has put now has been great, but they have to make sure that the primary teachers are going to continue to be able to develop that language capacity' (Teacher 5). As the focus in this article is on primary modern languages, it is perhaps not appropriate to discuss other areas of the curriculum, however, it is important to note another major government initiative, launched in 2016 with $£ 1.5$ million for training programmes and classroom resources, which aims to 'boost maths and science learning in primary schools.' (Scottish Government, 2016a, 2016b, 2016c). This most recent initiative may lead to a conflict of priorities for the primary teachers and schools as to which curricular area needs more attention.

Professional development courses organised by the Development Officers were identified as helpful, however, as one teacher pointed out: 'Some of the CPD (continuing professional development) sessions gave good ideas but the same resources I was using with my P4 class have been used by my colleague in her P6 class. So what happens when my P4s go to P6?(Teacher 7)' This seems to highlight an important issue regarding non-specialist primary teachers, who may not have the depth of language knowledge or the understanding of how to tailor resources and adapt activities to different age groups or stages of language learning. A greater number of opportunities for developing appropriate methodology was seen as vital: ' $I$ 
think someone to support us is important. I've got Higher French, but that was many years ago, and the only training I've had to teach French is a one day course' (Teacher 8). The Nuremberg recommendations state that primary teachers 'should work intensively and actively on (further) developing their competences and where appropriate should themselves take steps to obtain sufficient continuing professional development' (on-line). However, this may be difficult if there are few opportunities provided by LAs, lack of free time to devote to 'intensive' development of competence and commercial programmes are seen as too expensive to undertake.

When asked about possible next steps for their own language learning, few of the teachers appeared interested in or willing to undertake formal study to increase their knowledge and understanding of a particular language, or language pedagogy, for example, engaging with research around early language learning and gaining understanding of theory (Tarone and Allwright, 2005). The teachers cited lack of time as one reason: 'I haven't got time to read research. It's too complicated' (Teacher 1). Others expressed scepticism regarding research and theory. 'These people don't know what it's actually like to teach the stuff in the classroom day to day' (Teacher 2). The apparent divide between theory and practitioners' views of what works in the classroom is something that has been recognised (Stenhouse 1975, Clarke 1994) however, McDonough (2006, cited in Ellis 2010) argues that engagement with research and theory can broaden teachers' views on language teaching and change practice for the better. Nonetheless, it seemed disappointing that most of the teachers did not seem prepared to invest their time or money in improving their knowledge and understanding. Another teacher stated that she had enquired about a University Postgraduate Certificate, but when informed that her employers would not pay the fees, she decided not to pursue it any further. 'It would have cost nearly $\$ 1000$ over two years. If the school or LA isn't going to pay, then I'm not doing it' (Teacher 4). Having already cited the overcrowded nature of the primary curriculum and concern about other policy initiatives, it may have been that teachers took a strategic decision to concentrate their professional learning on a curricular area that they felt more familiar with.

\section{Discussion:}

The teachers in the study were all very enthusiastic about the $1+2$ initiative. It was perhaps as a result of their enthusiasm that they had volunteered to take part in the professional development courses offered by the four local authorities to develop their ML skills and competences.

Reinforcing their positivity regarding language learning was their belief that language learning was easier for young children than a later start. The majority of the teachers expressed the belief that '... children learn languages easier than adults' (Teacher 3); 'It is so much easier for primary pupils to learn to speak languages when they are younger rather than at secondary school, as they can get a better pronunciation ...' (Teacher 6), although they were unable to cite any research evidence to support their claims. In fact, as noted above, the most recent research seems unequivocal that early language learning outwith an immersion setting is not necessarily 'better' in terms of language gains themselves other than 
attitudinal gains (Muñoz, 2006a, 2006b, 2008; Myles n.d.) so that the teachers' assessment might be considered misinformed.

Proponents of the 'critical age hypothesis' suggest that children learning a language at a young age might achieve native speaker-like pronunciation (Patkowski 1980, DeKeyer and Larson-Hall, 2005) although this has been refuted (Cummins 1981, Abrahamsson and Hyltenstam, 2009). In terms of fluency, vocabulary acquisition, and accuracy, it is claimed that late starters outperform young learners, given the same language input (Mora 2006, Miralpeix 2006, Muñoz 2006a, Myles n.d.). Dekeyser (2000) argues that native speaker proficiency can only be assured through 'massive exposure' to language input. 'Exposure needs to be intense and to provide an adequate model' (Muñoz 2006b:34) 'Massive' exposure cannot be assumed to take place in a primary classroom with a generalist teacher. It is unlikely therefore, that however enthusiastic the teachers are, they will able to provide the intensity of language input and interaction necessary to produce deep learning, as recommended by Long (1996) or Mackey, (2012), for example, who both make the case for sustained interaction with both a focus on form and the close connection between input, output and feedback as a means of acquiring a language.

Despite enthusiasm for the initiative, the teachers expressed concern about their current level of proficiency and understanding, particularly with regard to pronunciation and grammar. As noted earlier, even well qualified teachers have reservations about using the target language extensively in the classroom (Meiring and Norman 2002; Klanrit and Sroinam 2012). The teachers in the study, many of whom considered themselves as beginners, appeared most concerned about providing incorrect models of language to their learners without the support of a native speaker or qualified specialist. Although the focus in the interviews was on the teachers themselves, a number mentioned colleagues who they described as less confident and less proficient. If this is indeed the case, this has worrying implications for the effective enactment of the policy, as it is intended that all primary teachers incorporate FL learning in their classrooms on a daily basis (Scottish Government,(2012a).

The teachers perceived Professional Learning opportunities as very helpful, but were also aware that they would need to be ongoing to ensure progression, so that they could develop their language skills to a level where they felt confident to incorporate a FL as part of their daily routine in the classroom at all levels. They also welcomed collaboration from secondary colleagues and native speakers who were viewed as valuable models for pronunciation and language usage. However, it was disappointing that so few of the teachers appeared to wish to invest time or money to develop their language learning formally, through postgraduate study for example, preferring a more practical 'tips for teachers' approach.

Interestingly, none of the teachers mentioned explicitly the links between literacy development and language learning, despite the emphasis in modern languages policy documentation on the interconnectedness of languages and knowledge about language (Education Scotland, 2012). Given the attention paid to literacy development by the Scottish Government $(2010,2015)$ and the clear messages from curricular policy, it seemed surprising that the teachers did not demonstrate more awareness of possible links between L1 and L2, 
nor in terms of the links between L2 and L3. This could be interpreted as worrying. It could be argued that the $1+2$ policy should offer more in depth consideration to the articulation and links between L1/L2/L3 for learners' language development encouraging practitioners to think of ways of developing literacy through study of FLs. Nor did they mention the development of intercultural awareness, which is also highlighted as an important part of language learning in the modern languages policy documents. Their concerns seemed wholly related to language proficiency, perhaps because this was seen as their most immediate challenge. Nonetheless, there may be a lost opportunity for fostering deep understanding of the relationship between language and culture (Kuang 2007; Kramsch 2013) and the importance of developing children's awareness and appreciation of other cultures, particularly in the multi-language, multi-cultural classrooms in which many of them work.

Conclusion:

This paper describes a piece of small scale research that aimed to explore a group of primary teachers' perceptions of their confidence in implementing the $1+2$ policy and also what they saw as helpful in supporting them to do so. The study has a number of shortcomings. It should be acknowledged that the fact that the teachers had all chosen to attend a course to improve their language skills and pedagogical approaches could be taken as evidence of a positive outlook towards the policy and it cannot be assumed that their colleagues and other primary teachers hold equally positive opinions. Certainly, there was some reference made by the participants to colleagues who may not have been in agreement with the policy. In addition, the small number of participants also meant that the findings cannot be generalised. A much larger study, encompassing teachers from a variety of LAs would provide more reliable findings and allow more robust conclusions to be made. Nonetheless, the findings indicate that there are some issues that need to be addressed if the policy is to be successful. The teachers in the study expressed great enthusiasm, but at the same time communicated anxiety about their levels of language and their understanding of pronunciation and grammar, which they indicated might become a serious issue as the policy unfolded, unless there was continued support. The main areas of support, native speaker modern languages assistants, secondary colleagues and professional learning providers were seen as essential for developing the teachers' competence and confidence, however, they also expressed concern that these supports should be sustained and sustainable long term. The issues of depth and progression were highlighted by almost all the participants. It seems crucial that teachers are given opportunities to continue to develop their competence within well-planned sustainable programmes of study, funded by the government, which not only address language proficiency but also the importance of intercultural appreciation and the contribution that language learning makes to literacy development if the policy is to be successful in the long term.

\section{References:}


Abrahamsson, N. and Hyltenstam, K. (2009) Age of Onset and Nativelikeness in a Second Language: Listener Perception Versus Linguistic Scrutiny. Language Learning 59, 2:249306.

Asselin, M. E. (2003). Insider research: Issues to consider when doing qualitative research in your own setting. Journal for Nurses in Staff Development, 19(2), 99-103.

Barton, A. and Boodhoo, N. (2009) Guest Editorial. The Language Learning Journal 37, 2: 141-143.

Bialystock, E. (2008) Second-Language Acquisition and Bilingualism at an Early Age and the Impact on Early Cognitive Development. In Encyclopedia on Early Childhood Development http://www.child-encyclopedia.com/sites/default/files/textesexperts/en/614/second-language-acquisition-and-bilingualism-at-an-early-age-and-theimpact-on-early-cognitive-development.pdf last accessed 19/05/2017.

Blumer, H. (1954). What is wrong with social theory? American Sociological Review 19, 1: 3-10.

Board, K. and Tinsley, T. (2015) Language Trends 2014/15: The state of language learning in primary and secondary schools in England. Berkshire: CfBT Education Trust.

Brookfield, S. (1995) Becoming a Critically Reflective Teacher. San Francisco: Jossey Bass.

Bryman, A. (2015) Social Research Methods ( $5^{\text {th }}$ edition), Oxford: OUP.

Carey, J. W., Morgan M., and Oxtoby M. J. (1996) Intercoder Agreement in Analysis of Responses to Open-Ended Interview Questions: Examples from Tuberculosis Research. CAM 8, 3: 1- 5 .

Cenoz, J. (2003) The Influence of Age on the Acquisition of English: General Proficiency, Attitudes and Code-mixing. In García Mayo, M.P. and García Lecumberri, M.L. (Eds) Age and the acquisition of English as a FL. Clevedon: Multilingual Matters.

Charmaz, K. (2003) Grounded theory: Objectivist and constructivist methods. In N. K.

Denzin and Y. S. Lincoln (Eds.), Strategies for qualitative inquiry ( $2^{\text {nd }}$ edition) (249-291). Thousand Oaks, CA: Sage.

Charmaz, K. (2006) Constructing Grounded Theory: A practical Guide Through Qualitative Analysis. London: Sage.

Clarke, M. (1994). The dysfunctions of theory/practice discourse. TESOL Quarterly 28.1, 926.

Crichton, H. and Templeton, B. (2010) An Evaluation of the Partial Immersion Project in St Aloysius College Junior School. Project Report. The University of Glasgow, Glasgow UK (unpublished) 
Cummins, J. (1981) Age on Arrival and Immigrant Second Language Learning in Canada: a Reassessment. Applied Linguistics 2, 1: 132-149.

Cummins, J. (1991) Language Development and Academic Learning Cummins, J in L. Malave, and G. Duquette, (Eds) Language, Culture and Cognition Clevedon: Multilingual Matters.

Cummins, J. (2000) Language, Power and Pedagogy: Bilingual Children in the Crossfire. Clevedon: Multilingual Matters.

Dekeyser, R. (2000) The Robustness of Critical Period Effects in Second Lnaguage Acquisition. Studies in Second Language Acquisition 22, 4: 499-533.

DeKeyser, R., and Larson-Hall, J. (2005). What does the critical period really mean? In J. F. Kroll and A. M. B. De Groot (Eds.), Handbook of bilingualism: Psycholinguistic approaches (pp. 88-108).Oxford: Oxford UniversityPress.Education Scotland (n.d.) Approach to language delivery from P1 onwards.

http://www.educationscotland.gov.uk/Images/PrimaryLanguageLearningOverarchingFramew ork_tcm4-833685.pdf last accessed 20/05/2017.

Education Scotland (2012) Curriculum for Excellence: Modern Languages Principles and Practice https://www.education.gov.scot/Documents/modern-languages-pp.pdf

Education Scotland (2015) Language Learning In Scotland: A 1+2 Approach. Further guidance on L3 within the 1+2 policy. http://www.educationscotland.gov.uk/Images/L3SupplementaryGuidance tcm4-852848.pdf last accessed 20/05/2017.

Ellis, R. (2010) Second language acquisition, teacher education and language pedagogy. Language Teaching 43, 2: 182-201.

Etikan, I, Musa, S. A. and Alkassim, S.R. (2016) Comparison of Convenience Sampling and Purposive Sampling. American Journal of Theoretical and Applied Statistics 5, 1: 1-4

European Council of Barcelona (2002) 'Presidency conclusions' Barcelona, European Council. http://ec.europa.eu/invest-in research/pdf/download_en/barcelona_european_council.pdf last accessed 23/05/2017.

Flick, U. (2014) An introduction to Qualitative Research. London: Sage

Franklin, C.E.M. (1990) Teaching in the Target Language: Problems and Prospects. Language Learning Journal 2, 1: 20-24.

García Mayo, M. P. (2003) Age, Length of Exposure and Grammaticality Judgements in the Acquisition of English as a FL. In García Mayo, M.P. and García Lecumberri, M.L. (Eds) Age and the acquisition of English as a FL. Clevedon: Multilingual Matters. 
General Teaching Council, Scotland (GTCS) (2013) Entry Memorandum and Guidelines Consultation Summary. http://www.gtcs.org.uk/web/FILES/about-gtcs/entry-memorandumand-guidelines-consultation-summary.pdf last accessed 23/05/2017.

Gillespie, J.H., Johnston, D. and Ó Corráin, A. (2012) Languages for the Future: Northern Ireland Languages Strategy. Department of Education, Northern Ireland https://www.deni.gov.uk/sites/default/files/publications/de/languages-for-the-future.pdf last accessed 14/04/2017.

Goethe Institut (2010) Nuremberg Recommendations for Early FL Learning http://www.goethe.de/lhr/prj/nef/enindex.htm

Hattie, J. (2012) Visible Learning for Teachers. Routledge: Oxon.

HMIe (2011) Gaelic Education: Building on the successes, addressing the barriers. http://www.educationscotland.gov.uk/Images/gebse tcm4-712947.pdf last accessed $14 / 05 / 2017$.

Holstein, J. A., and Gubrium, J. F. (1995) The active interview (Vol. 37). London, UK: SAGE.

Johnstone, R., Harlen, W., MacNeill, M., Stradling, B. and Thorpe, G. (1999) The Attainments of Pupils Receiving Gaelic-medium Primary Education in Scotland. Stirling: Scottish CILT.

Johnstone, R.and McKinstry, R. (2008) Evaluation of EPPI: Early Primary Partial Immersion in French at Walker Road PrimarySchool, Aberdeen. Final Report. Stirling, SCILT.

Jones, M. (2001) The Welsh Language in Education in the UK. Leeuwarden: MercatorEducation

Klanrit, P. and Sroinam, R. (2012) EFL Teacher's Anxiety in Using English in Teaching in the Language Classroom. International Journal of Social Science and Humanity 2, 6: 493 496.

Kramsch, C. (2013) Culture in FL Learning Iranian Journal of Language Teaching Research. $1,1: 57-78$.

Kuang, J. F. (2007). Developing students' cultural awareness through FL teaching. Sino-US English Teaching, 4(12), 74-81

Kultus Minister (2013) Bericht „Fremdsprachen in der Grundschule - Sachstand und Konzeptionen 2013 "Beschluss der Kultusministerkonferenz vom 17.10.2013 http://www.kmk.org/fileadmin/Dateien/veroeffentlichungen_beschluesse/2013/2013_10_17Fremdsprachen-in-der-Grundschule.pdf last accessed 20/05/2017.

Lincoln, Y.S. and Guba, E. G. (1985) Naturalistic enquiry. Beverly Hills: Sage. 
Lohmar, B. and Eckhardt, T (2014) The Education System in the Federal Republic of Germany 2012/2013 Bonn:Secretariat of the Standing Conference of the Ministers of Education and Cultural Affairs of the Länder in the Federal Republic of Germany.

Long, M.H. 1996. The role of the linguistic environment in second language acquisition. In W.C. Ritchie and T.K. Bhatia (eds) Handbook of Second Language Acquisition (pp. 413468). New York: Academic Press.

Mackey, A. 2012.Input, Interaction and Corrective Feedback in L2 Classrooms. Oxford: Oxford University Press.

Meiring, L. and Norman, N. (2002) Back on target: repositioning the status of target language in MFL teaching and learning. Language Learning Journal 26, Winter: 27-35.

Ministère de l'Education l'Enseignement National de 1'Enseignement Supérieur et de la Recherche. (2016) Qui enseigne les langues à l'école?

http://eduscol.education.fr/cid45714/qui-enseigne-les-langues-a-l-ecole.html last accessed 23/05/2017.

Ministerio de Educación, Cultura y Deporte Consejo Escolar Del Estado (2012) Dictamen $27 / 2012$

http://www.mecd.gob.es/dctm/cee/elconsejo/dictamenes/2012/dictamen0272012.pdf?docume ntId=0901e72b8141babd Last accessed 22/06/16

Miralpeix, I. (2006) Age and Vocabulary Acquisition in English as a FL. In Age and the Rate of FL Learning. C. Muñoz (Ed.) Clevedon: Multilingual Matters.

Mora, J. (2006) Age Effects on Oral Fluency Development. In Age and the Rate of FL Learning. C. Muñoz (Ed.) Clevedon: Multilingual Matters.

Muñoz, C. (2006a) Accuracy Orders, Rates of Learning and Age. In Age and the Rate of FL Learning. C. Muñoz (Ed.) Clevedon: Multilingual Matters.

Muñoz, C. (2006b) The Effects of Age on FL Learning: the BAF project. In Age and the Rate of FL Learning. C. Muñoz (Ed.) Clevedon: Multilingual Matters.

Muñoz, C. (2008) Symmetries and Asymmetries of Age Effects in Naturalistic and Instructed L2 Learning. Applied Linguistics 29, 4: 578-596.

Muñoz, C. and Singleton, D (2011) A critical review of age-related research on L2 ultimate attainment. Language Teaching, 44, 1: 1-35.

Myles, F. (n.d.) The role of age in L2 learning ESRC funded study The role of age in L2 learning. https://www.essex.ac.uk/langling/research/ladeli/language-learning.aspx last accessed 24/05/2017. 
Nightingale, D.J. and Cromby, J. (1999) (Eds.), Social constructionist psychology: A critical analysis of theory and practice. Buckingham: Open University Press.

O'Hanlon, F., McLeod, W. and Paterson, L. (2010) Gaelic-medium Education in Scotland: choice and attainment at the primary and early secondary school stages. 'The Output of Gaelic Education', funded by Bòrd na Gàidhlig: Edinburgh University

Paradis J., Crago M., Genesee F. and Rice M. (2003) French-English bilingual children with SLI: how do they compare with their monolingual peers? Journal of Speech, Language, and Hearing Research : Jslhr. 46, 3: 113-27.

Patkowski, M. (1980) The Sensitive Period for the Acquisition of Syntax in a Second Language. Language Learning 30, 2: 449 -742.

Plesner, U. (2011) Studying Sideways: Displacing the Problem of Power in Research Interviews with Sociologists and Journalists. Qualitative Inquiry 17, 6: 471-472.

Rubin, H.J. and Rubin, I. S. (2012) Qualitative Interviewing: The Art of Hearing Data. (3 ${ }^{\text {rd }}$ Edition). London: Sage.

Scottish Government (2010) Literacy Action Plan: An action plan to improve literacy in Scotland http://www.gov.scot/Publications/2010/10/27084039/0

Scottish Government (2012a) Language Learning in Scotland: A 1+2 Approach http://www.gov.scot/Publications/2012/05/3670/downloads

Scottish Government (2012b) Government's Response to the Report of the Languages Working Group.

http://www.gov.scot/Topics/Education/Schools/curriculum/ACE/LanguageLearning/SGResp onse-Revised last accessed 22/05/2017.

Scottish Government (2015) The Final report from the Standing Literacy Commission on the Scottish Government's Literacy Action Plan. http://www.gov.scot/Publications/2015/04/4553

Scottish Government (2016a) Science, Technology, Engineering and Mathematics:

Consultation for a Strategy for Education and Training. Scottish Government: Edinburgh

Scottish Government (2016b) Delivering Excellence and Equity in Scottish Education: A Delivery Plan for Scotland http://www.gov.scot/Publications/2016/06/3853

Scottish Government (2016c) Newsroom: $£ 1.5$ million for STEM subjects. https://news.gov.scot/news/15m-for-stem-subjects

Scottish Parliament, External Relations Committee (2013) 3rd Report, 2013 (Session 4) FL learning in primary schools. SP Paper 361.

Silverman, D. (2005) Doing Qualitative Research (2 ${ }^{\text {nd }}$ Edition). London: Sage. 
Stein, F. Rice, M.S. and Cutler, S.K. (2013) Clinical Research in Occupational Therapy. Delmar: Cengage Learning.

Strauss, A.L. (1987) Qualitative Analysis for Social Scientists. Cambridge: Cambridge University Press.

Strauss, A.L. and Corbin, J. (2008) Basics of Qualitative Research ( $3^{\text {rd }}$ edition). London: Sage.

Stenhouse, L. (1975). An introduction to curriculum research and development. London: Heinemann.

Tarone, E. and Allright, D. 2005. Second language teacher learning and student second language learning: Shaping the knowledge base. In D. Tedick (ed). Second Language Teacher Education: International Perspectives (pp. 5-23). Mahwah, NJ: Lawrence Earlbaum.

Tierney, D, (2011) FL teaching in the primary school: meeting the demands. In Applied Linguistics and Primary Teaching S. Ellis, and E. McCartney, (Eds.) Cambridge: Cambridge University Press.

Tierney, D. and Gallestegi L. (2013) Learning new languages is now a primary concern. Times Educational Supplement 26 ${ }^{\text {th }}$ April 2013. https://www.tes.com/article.aspx?storycode=6331308 last accessed 20/05/2017.

Tinsley, T. and Board, K. (2016) Language Trends in Wales, 2015/16. Reading: Education Development Trust

Appendix 1: Teacher participants' experience and stated qualifications.

\begin{tabular}{|l|l|l|l|}
\hline Teacher & $\begin{array}{l}\text { Experience } \\
\text { teaching }\end{array}$ & $\begin{array}{l}\text { Primary } \\
\text { Teaching } \\
\text { Qualification }\end{array}$ & $\begin{array}{l}\text { Level of Linguistic } \\
\text { competence }\end{array}$ \\
\hline Teacher 1 & 5 years & BEd (hons) & Higher French \\
\hline Teacher 2 & 10 years & BEd (hons) & $\begin{array}{l}\text { Standard Grade level 3 } \\
\text { Spanish }\end{array}$ \\
\hline Teacher 3 & 8 years & PGDE & $\begin{array}{l}\text { 1 year French in } \\
\text { undergraduate degree; } \\
\text { MLPS training in } \\
\text { French }\end{array}$ \\
\hline Teacher 4 & 14 years & PGDE & none \\
\hline
\end{tabular}




\begin{tabular}{|l|l|l|l|}
\hline Teacher 5 & 3 years & BEd (hons) & $\begin{array}{l}\text { Higher French, Higher } \\
\text { Spanish }\end{array}$ \\
\hline Teacher 6 & 19 years & BEd (hons) & $\begin{array}{l}\text { Standard Grade level 2 } \\
\text { Spanish; MLPS } \\
\text { training in French }\end{array}$ \\
\hline Teacher 7 & 6 years & PGDE & $\begin{array}{l}\text { Degree in French and } \\
\text { Business }\end{array}$ \\
\hline Teacher 8 & 21 years & PGDE & Higher French \\
\hline Teacher 9 & 6 years & BEd (hons) & none \\
\hline Teacher 10 & 12 years & PGDE & none \\
\hline
\end{tabular}

Explanation of qualifications:

'Standard Grade' is roughly equivalent to GCSE in the English system and is graded 1-7, 1 being the highest.

'Higher' is the benchmark exam for entry to university and is roughly equivalent to A Level in the English system.

Modern Languages in the Primary School (MLPS) refers to training courses organised by local authorities which lead to a professional qualification to teach a modern language in the primary school. 